Ethiopian Journal of Environmental Studies \& Management 9(5): 579 - 592, 2016.

ISSN:1998-0507

doi: http://dx.doi.org/10.4314/ejesm.v9i5.5

Submitted: February 24, 2016

Accepted: September 07, 2016

\title{
OUTDOOR RECREATIONAL BEHAVIOURS AND PREFERENCES OF ABUJA RESIDENTS, NIGERIA
}

\author{
*SULYMAN, A.0. ${ }^{1}$ AND IORLIAM, S.T. ${ }^{2}$ \\ ${ }^{1}$ Department of Urban and Regional Planning, Federal University of Technology, Minna, \\ Nigeria \\ ${ }^{2}$ Department of Urban and Regional, Planning Benue State University Makurdi, Nigeria
}

\begin{abstract}
This study analyzed the recreational behaviours and preferences of residents of the federal capital city Abuja. The survey research design was adopted whereby structured questionnaires were used to elicit data from 400 randomly selected respondents through oral interviews. Descriptive statistical tools including averages, percentages, chi square test and bar charts were utilized in the analysis of the field data. Result of the investigation revealed that despite the heterogeneous nature of the sampled population of the central city, recreational activities occupy over $65 \%$ of the respondents' leisure time, only $35 \%$ of the sampled respondents usually engage in non recreation activities. Again the result revealed six most preferred activities of recreation by majority (58\%) of the sampled population which include watching soccer matches/other games in parks, playing soccer, taking beer/other drinks, bicycle riding, visiting museums and trekking. However, the result also indicates that the relative importance of these preferred recreational activities vary with age, gender, educational attainments and income levels of the residents. For effective recreation planning therefore, it has been recommended that the allocation of resources for recreational facilities in the city should not only reflect the preferences of the larger percent of the participants in these categories, but should also reflect that of the minorities in the same age, gender, education and income status. This will act as a guide towards adequacy of the facilities for the needs of all groups thereby averting underutilization of facilities or their over utilization by the citizens.
\end{abstract}

Key words: Recreation, Behavior, Activity preference, Social status, Livability

\section{Introduction}

In the city, one major activity that reduces stress arising from men's daily hassles and struggles for existence that also enhances the livability of cities is recreation. Manifesting in various forms -indoors and outdoors, active and

\footnotetext{
*Corresponding Author: Sulyman, A.O.

*Corresponding Author: Sulyman
Email: sulymanlance@gmail.com
}

passive, or communal and solitary, recreation provides the urban man with a refreshing break from the monotonous city life by providing opportunities to socialize and pursue hobbies that are a source of joy and relaxation to the body and mind. Consequently, for most city 
governments, providing recreational facilities that would meet the needs of the residents has always being given high priority in policy formulation and land use planning.

In Nigeria's new Federal Capital City Abuja, the increasing diversity of the urban population due to rapid population influx has posed a great challenge to the authorities that wish to meet the leisure needs and preferences of its citizens. Attempts by the city administrations over time often fail due to dearth of requisite knowledge of the peoples' recreational needs and preferences. Thus, even though some of the planned open spaces and green areas along fragile lands have been developed as recreation sites, some of these spots are poorly patronized or underutilized and in some cases even converted to other urban uses (Jibril, 2010).

Although at the global levels there exist much literature on recreational preferences of the urban populations, most of these are based on research conducted from cities in foreign lands and advanced societies (Riddick and Stewart, 1994; Dwyer and Barro, 2001; Payne et al, 2002; Kara and Demirci, 2010). Consequently, the research results cannot be guaranteed to fully address the needs and preferences of the local urban population in a developing nation.

This investigation is set out to provide a better understanding of the recreational behaviors and preferences of local residents of the Federal capital City Abuja. Therefore the next section of this paper reviews some conceptual issues from literature. This is followed by highlights of the study area and the research methodology in sections three and four while the results of investigation are presented in section five.

\section{Conceptual Issues}

The word 'Recreation' stems from the Latin word "recreatio", meaning that which refreshes or restores. MerriamWebster Dictionary therefore defines recreation as a means of refreshment of strength and spirit after work. Similarly Austin (2003) considered recreation as a period of light and restful activity, voluntarily chosen, that permits one to regain energy after heavy work and to return to work renewed. These definitions have however been criticized on the grounds that they do not cover the case of persons who have no work including the growing retiree population, but who certainly need recreation to make their lives meaningful (Gray and Grebin, 1974). Consequently, Broadhurst (2001) simply defined the concept recreation as any activity that people engage in when at leisure for enjoyment or usually to refresh the body and mind. Such activities are multifaceted: they can be communal or solitary, active or passive, healthy or harmful and people could engage in them either indoors or in the outdoors.

Outdoor recreation is leisure pursuits engaged in the outdoors, especially away from home and sometimes in natural or semi-natural settings like parks, wilderness or out of town. It may also include team sport game or practice held in an outdoor setting. These include kinds of activities like visiting areas such as parks, museums, wilderness areas, lakes, rivers, and forest as well as engaging in different exercises such as trekking, fishing, hunting, and camping.

There are several benefits that can be derived from recreation such as 
maintaining one's physical and mental health, strengthening relationships among family members, increasing performances in business life, reducing crime rates, and making individuals more integrated with societies. However, these gains according to Kara and Dermici (2010) could be drawn only after a certain amount of participation has been achieved. Nevertheless, many people's participation levels in activities of recreation are limited because of several factors. Scot and Jackson (1996) refer to those factors militating against participation levels as recreational constraints. And according Crawford and Godbey (1987), the constraints can be classified in to three categories namely, structural constraints, intrapersonal constraints and interpersonal. Structural constraints relates to the recreational sites or spots, their facilities, and availability of access to them. Intrapersonal constraints to recreation consist of the psychological conditions and characters of people such as their personality, emotions, moods, and attitudes. On the other hand, interpersonal constraints the authors include personal attributes such as social status variables like age, income levels, gender and family circle. The amounts of limitations imposed by these recreational constraints vary from one person to another and often from one society to another depending on social values and traditions. Despite the variations however, these recreational constraints individually or collectively act together to shape a people's recreational behavior and preferences.

Recreational behaviors and preferences therefore reflect the ways in which people of different social status compose themselves during leisure time and respond to their recreational needs in terms of their inclination towards certain recreational areas, and recreational activities. This is central to sustainable outdoor recreational planning. This is because according to Zandersen and Tol (2008) understanding recreational behaviors and preferences of the residents of different socio-economic strata ensures the development of only desirable recreation infrastructure in the community that are adequate and can be maximally utilized by all residents.

Consequently, several studies have been carried out on the behavior and preferences of people in different climes. Patmore (1983) reviewed leisure patterns based on place variations and discussed how behavioral indicators associated with settings (e.g., participation rates or attitudes) were explained by the distribution and allocation of recreation opportunities. Also, Haley (1979, 1985) analysed the allocation of park land areas and recreation expenditures across various residential locations. He found that while there were opportunity gaps in recreation services among cities and suburbs, these gaps had narrowed somewhat over time. Schroeder (1983) also explored park-setting preferences between urban residents and suburban/rural residents. He found that respondents who had spent most of their life in urban areas were more likely to prefer developed parks, while those from suburban/rural backgrounds were more likely to prefer natural forest environments.

Furthermore, several authors have also investigated the influences of social status on recreational behavior and the preferences of residents in the city. In his study of the pattern of recreation 
activities in United Kingdom, Roskaft (2004) predicted preference for outdoor recreation activities based on age and gender. Specifically, it was found that men dominate high-risk activities like hang gliding, parachute jumping and mountain climbing, while women dominate gathering activities. In terms of age, activities like hunting and fishing were distributed among men of more similarly age groups. Also, Kara and Demirci (2010) discovered from their research in Istanbul city in Turkey that males of age ranges from 25 to 35 years were more active in swimming, trekking and picnicking than the older men folk. They again discovered that the low income earners in Istanbul city dedicated more time to participating in outdoor recreational activities such as cycling of bicycles and fishing than the high income earners. However in their recreational studies in Minna town Nigeria, Nelson et al. (2013) discovered that most low income earners prefer to spend more time in viewing of international soccer matches and walking round the city during leisure. They reiterated that most Minna residents do not partake in outdoor recreation due to poverty, time constraints, culture and inadequate recreational facilities in the city. In the United States of America, Backer (2013) discovered that it is women of between 20 years to 40 years that frequently indulge in watching of Television in parks at their leisure time.

These studies by Kara and Demirci (2010) in Turkey; Backer (2013) in USA, and Nelson et al. (2013) in Nigeria have provided exciting revelations of the variations in the outdoor recreational behaviors and preferences of the people across cultures with respect to the socio- economic variables like age, gender and income. These variations are significant in recreational planning and have come to consolidate the fact that recreational behaviors and preferences of the people are case specific. This implies that citizens of each city or nation vary in their recreational experiences and therefore for any recreation plan of any city to be effective, a case specific research based on detailed investigation of the recreational needs and preferences of the targeted people becomes paramount.

\section{Study Area}

Abuja, the Federal Capital City of Nigeria can be located at latitude $9^{\circ} 4^{\prime} 0^{\prime \prime}$ North of the Equator and longitude $7^{\circ} 29^{\prime} 0^{\prime \prime}$ East of the Greenwich meridian. The city officially became Nigeria's capital on $12^{\text {th }}$ December 1991. Since then, Abuja has witnessed a tremendous population growth. Population projections from the 2006 Nigerian census show that by 2012, the city of Abuja had a population of 979,876 people; this makes it one of the ten most populous cities in Nigeria.

According to the official master plan, Abuja was designed to be built in 4 phases. At present, only the phase I area known as the central city has been developed fully. The phase I area of the city covers a total area of 7076 hectares. Out of this, about $18 \%$ or 1260 hectares is reserved for 'Greens' development (Jubrill 2010). This includes open spaces and sites for recreational facilitiessuch as: parks, gardens and children playgrounds, out door games, sport centers, national and district/neighborhood parks.

Apart from developed parks, green open lands are preserved along fragile hillsides, valleys, and along streams /river courses to preserve the top soil from denudation by erosion and landslides. 
Ethiopian Journal of Environmental Studies and Management Vol. 9 no.5 2016

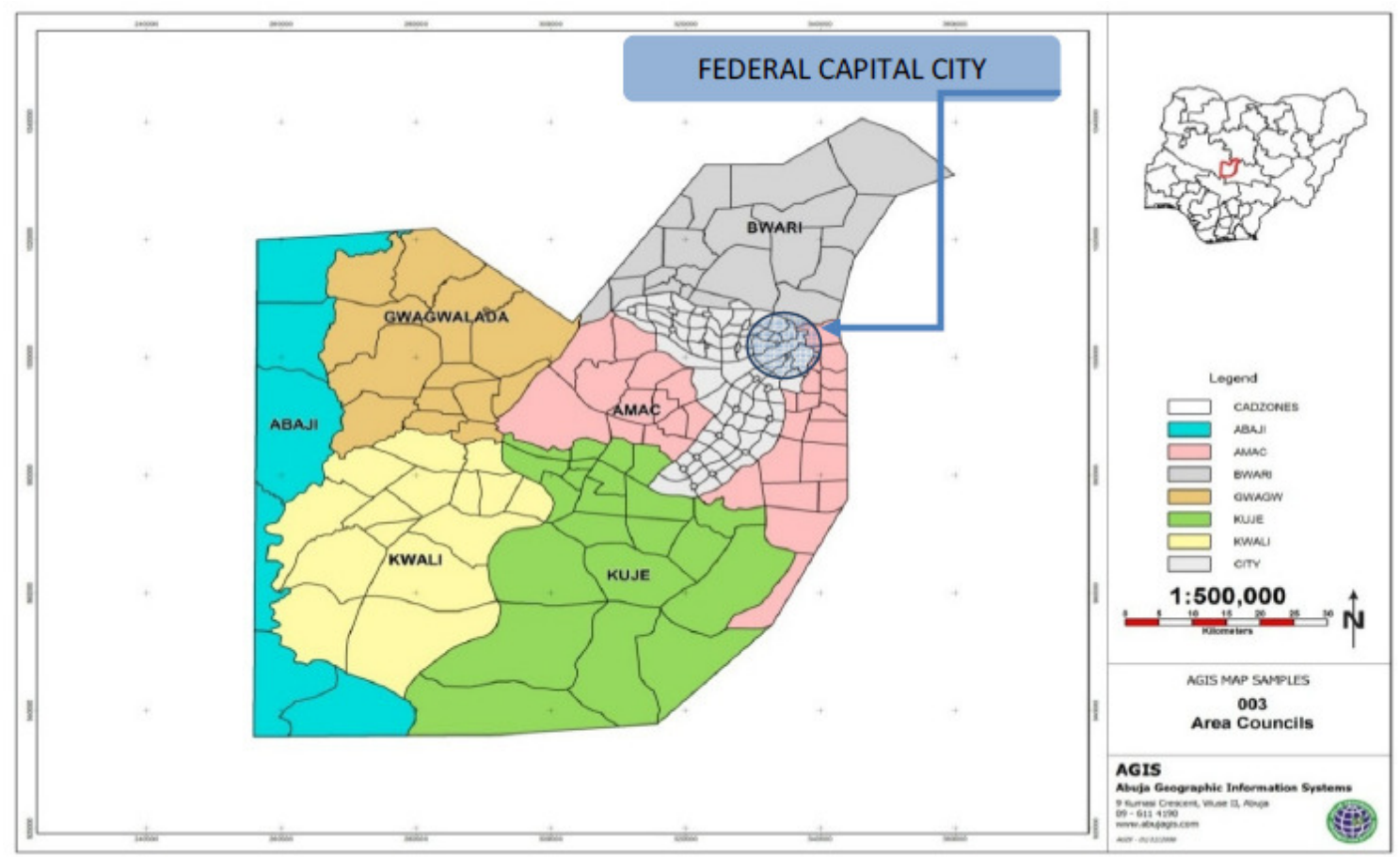

Figure 1: Federal Capital Territory Abuja showing the Federal Capital City (FCC)

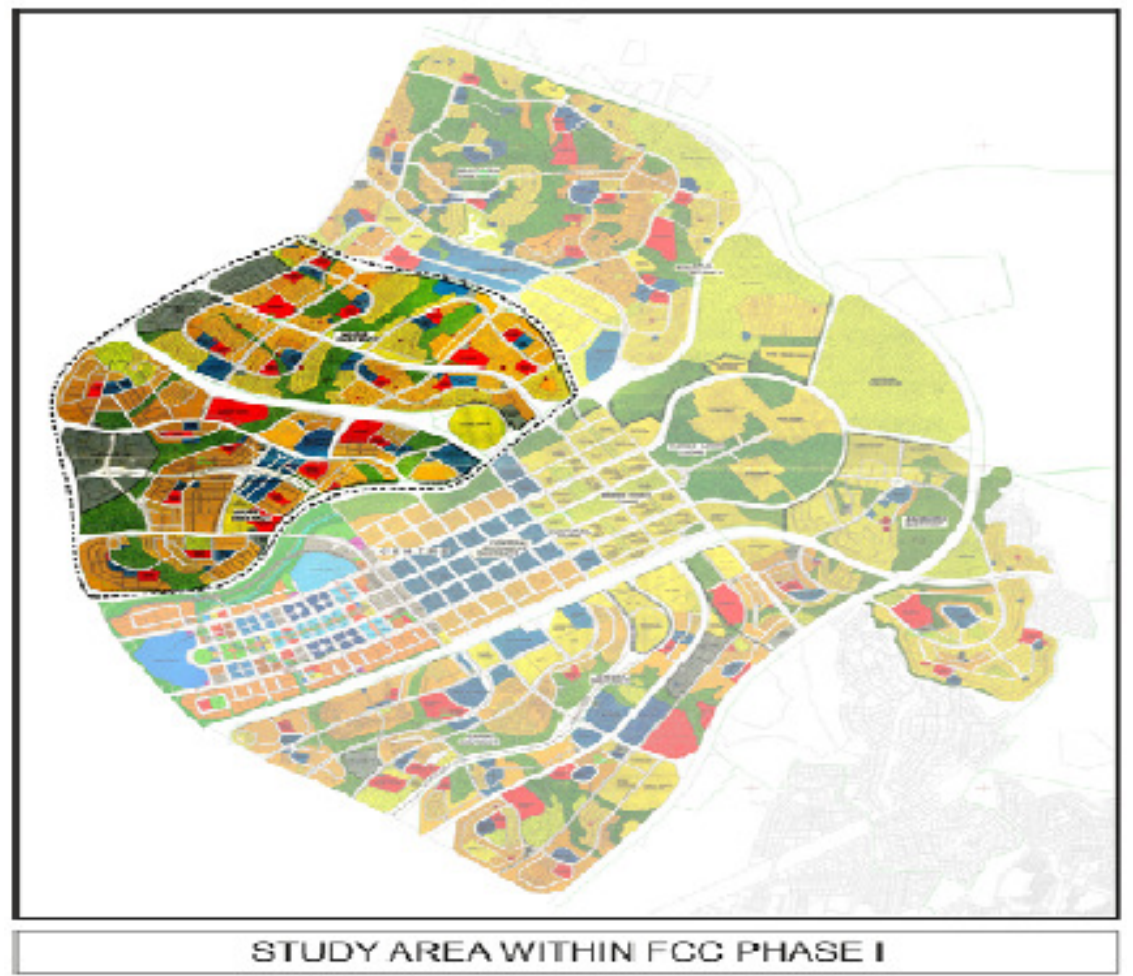

Figure 2: Study Area within FCC Phase I

Source: Abuja Geographical Information System (AGIS) 


\section{Materials and Methods}

The survey research design was adopted for this study. The survey covered 4 districts of Abuja Municipal Area Council (the central city) namely Wuse I, Wuse II, Garki I and Maitama. The targeted population for the study was people who have lived in Abuja Municipal Area Council (the central city) for at least five years. And considering the estimated population of the central city, 100 respondents were selected randomly from each residential district so that at the end, a total of 400 residents were contacted and interviewed. Structured questionnaire was the major instruments for collecting data from the sampled respondents. The questionnaire consisted of three sections. The first section sought personal sociodemographic information of the respondents like age, gender, educational level, monthly income, and occupation. The second section requested information about types of activities the participants engaged in during leisure. To investigate the extent to which recreational activities occupy residents' leisure time, sampled participants were first asked to state what they do in their spare time (without giving them any choice option). Then the respondents were subsequently asked to indicate the type of outdoor recreational activities that they would prefer to engage in during recreation from a list of outdoor activities of recreation presented to them (such as picnicking, swimming, hunting and trekking, soccer sports etc). The aim of this question was to understand which outdoor recreational activities are preferred by the residents of Abuja. The data collected were analyzed using descriptive statistical tools such as frequencies, percentages and averages while chi square statistic was used to test the significance of the results.

\section{Results and Discussion \\ Socio-economic Characteristics of Respondents}

The findings on these socio-economic data are tabulated in Table 1. The investigation results shows that $68.5 \%$ of the sampled respondents were males while $29.5 \%$ were females. Also, the study shows about one third of the sample aged between 18 and 30 years; one quarter was within 31-40years while those within 41 - 50 years age ranges and even older constituted $45.6 \%$ of the sample population collectively. In terms of educational attainments, $22.75 \%$ of the sampled respondents had no higher than Senior Secondary School certificates (SSCE) while $33.6 \%$ had tertiary education qualifications. 
Table 1: Socio-Economic Characteristics of Respondents

\begin{tabular}{|c|c|c|}
\hline $\begin{array}{l}\text { Age ranges of Respondents } \\
\text { (years) }\end{array}$ & Frequency & Percentage \\
\hline Below 30 & 116 & 29.0 \\
\hline $30-40$ & 102 & 25.5 \\
\hline $41-50$ & 135 & 33.8 \\
\hline $51 \&$ Above & 47 & 11.8 \\
\hline Total & 400 & 100.0 \\
\hline \multicolumn{3}{|l|}{ Gender } \\
\hline Male & 274 & 68.5 \\
\hline Female & 126 & 31.5 \\
\hline Total & 400 & 100.0 \\
\hline \multicolumn{3}{|l|}{ Qualification } \\
\hline No Formal Education & 20 & 5.0 \\
\hline SSCE & 71 & 17.75 \\
\hline Diploma/NCE & 131 & 32.75 \\
\hline $\mathrm{BSc} / \mathrm{HND}$ & 125 & 31.25 \\
\hline P G up to Master's Degree & 42 & 10.50 \\
\hline Ph.D & 11 & 2.75 \\
\hline Total & 400 & 100.0 \\
\hline \multicolumn{3}{|l|}{ Employment Status } \\
\hline Private sector/Self employee & 241 & 60.25 \\
\hline Public/Civil Sector & 117 & 29.25 \\
\hline Unemployed & 42 & 10.50 \\
\hline Total & 400 & 100.0 \\
\hline \multicolumn{3}{|l|}{ Income category ( } \\
\hline Below 20,000 & 26 & 6.50 \\
\hline $21,000-50,000$ & 66 & 16.50 \\
\hline $51,000-100,000$ & 98 & 24.50 \\
\hline $101,000-150,000$ & 122 & 30.50 \\
\hline Above 150,000 & 88 & 22.00 \\
\hline Total & 400 & 98.50 \\
\hline
\end{tabular}

Furthermore, those with university degree or its equivalent constituted $31.25 \%$ of the sample while another $13.25 \%$ acquired post graduate qualifications. In another dimension, the study revealed that over $80 \%$ of the sampled population was employed. Out of these more than half are in private sector employments while. Government employees constituted one third of the population while remaining $10.50 \%$ of the sampled population are unemployed.
The analysis of monthly incomes of the sampled respondents (in Naira-N) shows that a greater percent of the residents $(52.5 \%)$ take home more than $\mathrm{N} 100,000$ monthly, and one quarter ( $24.5 \%$ ) earn between N51, 000 - N100,000 while those earning below N50, 000 monthly constituted $23.0 \%$ of the population.

The foregoing analysis shows that the study population is sociodemographically heterogeneous in nature. This may have implications on their 
recreational activity preferences and even their recreational behavior in the city.

Recreational Behaviors of Residents in Abuja

The sampled population was asked to freely state how they spent their spare time without been given any options. Their various responses are grouped into four categories for the purpose of understanding whether the activities participants engaged in were recreational or not in Table 2. The categories include: "indoor recreational activities", "outdoor recreational activities", "visiting and chatting with friends and relatives", and "non-recreational activities".

Table 2: Respondents Activities during Spare Time

\begin{tabular}{lll}
\multicolumn{1}{c}{ Activity } & Responses & Percentage \\
\hline Visiting friends /relations & 22 & 5.50 \\
Outdoor recreation & 147 & 36.75 \\
Indoor activities & 114 & 28.50 \\
None recreational & 117 & 29.25 \\
Total & 400 & 100 \\
\hline
\end{tabular}

According to results in the table about one third of the selected sample population $(29.25 \%)$ indulge in none recreational activities like shopping, cooking or cleaning and etc while 5\% use the spare time for visiting friends and relations during their spare moments. On the other hand responses of over $65 \%$ of the sampled residents' show they indulge in various forms of recreational activities during their spare time. Out of this, about $28.50 \%$ of the population engages in passive indoor activities like watching movies and listening to radio while the larger percent $(36.75 \%)$ partake in various outdoor recreation activities. This result has therefore provided us remarkable understanding of the extent to which recreational activities occupy the residents' spare time in Abuja.

\section{Outdoor Recreational Activity Preferences of Residents}

A list of 18 outdoor recreational activities earlier selected from literature was presented to participants in a table, and they were asked to show which of the activity they would prefer to engage in most for recreation. The result shows that, watching soccer games in parks, playing soccer matches, taking drinks with friends in bear parlours, bicycle riding and trekking around town are clearly the most preferred recreational activities among $58 \%$ of the participants. In the main, watching soccer/games in parks and playing soccer are the most preferred recreational activities as more than one third or $31.75 \%$ of the participants choose watching and playing or soccer matches and other games in recreation parks. The third most preferred recreational activity is drinking beer at public beer parlours/bars and parks. About $10.8 \%$ of the participant population chose visiting beer parlours and drinking joints to share drinks during recreation. On the other hand, 8.55 and $7 \%$ of the participants opted for taking a ride on bicycles and visiting historical Museums respectively thereby making these activities the fourth and fifth most preferred in the city respectively. As 
results in the table further indicates, taking a walk $(5.75 \%)$, picnicking $(5.0 \%)$, and visiting Zoological gardens $(5.0 \%)$ as well as taking photographs and visiting and chatting with friends also constitute important activity for recreation as these attract significant votes from the sampled population under study.

\section{Table 3: Recreational Activity Preferences of Sampled Abuja City Residents}

\begin{tabular}{lll}
\hline Outdoor Recreational Activity & Frequency & Percentage \\
\hline Playing/ Soccer & 42 & 10.5 \\
Swimming & 8 & 2.0 \\
Bicycle riding & 34 & 8.5 \\
Taking Photographs & 16 & 4.0 \\
Visiting /Chatting with friends & 15 & 3.75 \\
Visiting Zoo & 19 & 4.75 \\
Visiting Museums & 28 & 7.0 \\
Visiting historical sites & 9 & 2.25 \\
Hunting games & 7 & 1.75 \\
Watching natural life in parks & 12 & 3.0 \\
Mountain Climbing & 3 & 0.75 \\
Walking or Trekking & 23 & 5.75 \\
Playing Basket ball & 17 & 4.25 \\
Picnicking & 20 & 5.0 \\
Playing Tennis & 8 & 2.0 \\
Visiting Wildlife parks & 11 & 2.75 \\
Watching soccer matches & 85 & 21.25 \\
Taking drinks in parks/bear parlours & 43 & 10.75 \\
\hline Total & 400 & 100.0 \\
\hline
\end{tabular}

On the other extreme, our study also revealed the least preferred activities of recreation in Abuja from the sampled population. As Figure 3 shows mountain climbing is the least preferred recreational activity among the participants; only 3 people or $0.75 \%$ of the population in the sample survey indicated that mountain climbing is their foremost activity of outdoor recreation.

Similarly, other activities such as hunting for games, swimming, playing tennis, visiting historical sites and wildlife parks as well as watching nature in the wilderness received less than $4 \%$ votes each from the participants as their most preferred recreational activity. For instance the result shows that while barely $1.75 \%$ voted for game hunting as an act of recreation, only 2.0 respectively voted for swimming and playing tennis and $2.25 \%$ voted for playing tennis. 


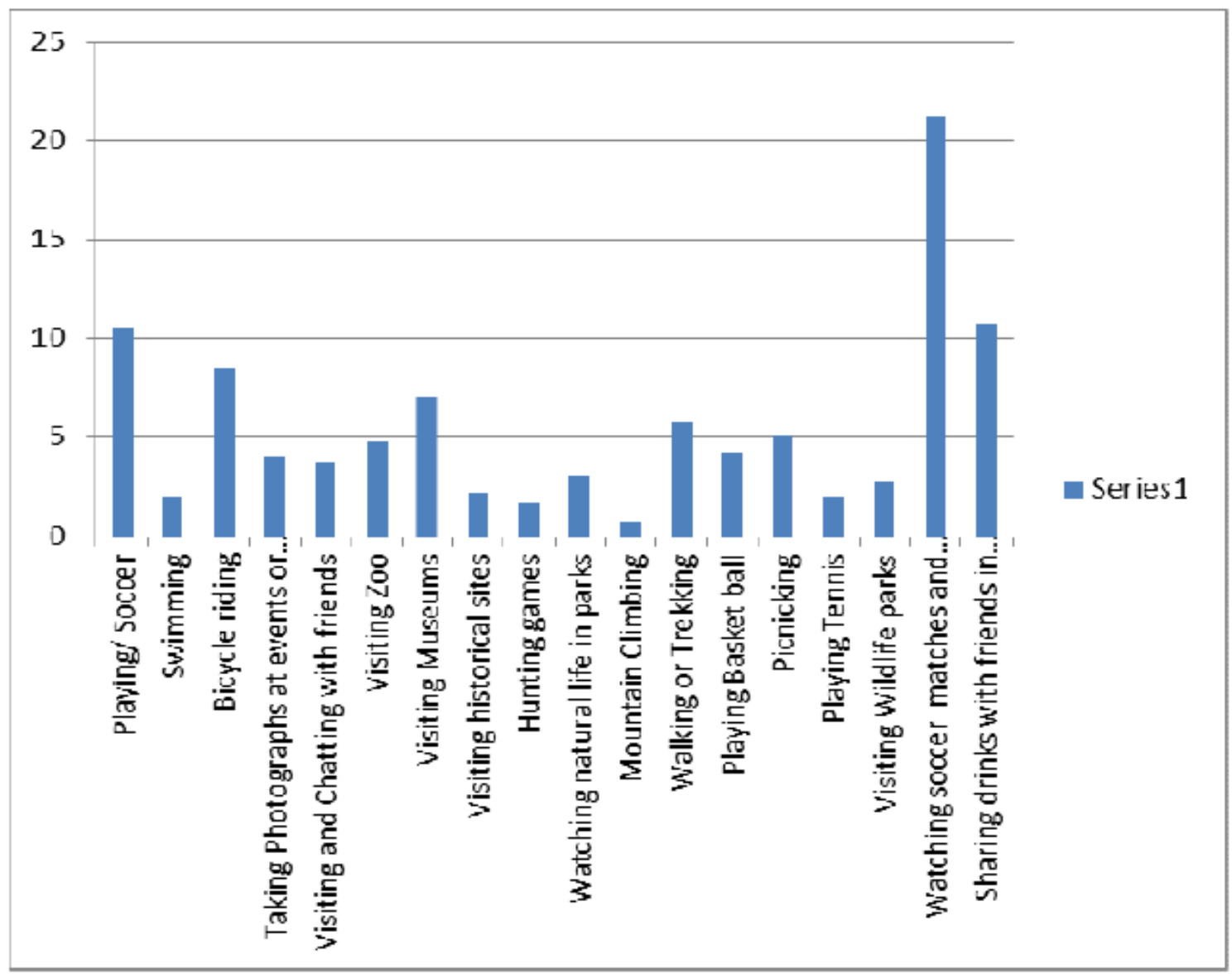

Figure 3: Recreational activity preferences of sampled Abuja residents

\section{Socio-Economic Status and Recreational Preferences of Abuja residents}

For the purpose of comparing the most preferred recreational activities of the different socio-economic groups of residents, the most preferred activity responses of the participants were regrouped according to -age, gender, educational level, and monthly income. The participants' votes on each activity are in percentages and the result has been presented in Table 4.

As the results in Table 4 indicates, watching soccer matches/other sports and playing soccer game as well as taking beer and other drinks in pubs and at parks, Bicycling, visiting museums and trekking around town are clearly the most preferred outdoor recreational activities among all groups of participants totaling almost $60 \%$ of the population sampled. Nevertheless, there are variations in the most preferred activities between the young and old, males and females, low and high educated people as well as between the low and high income earning participants. 
Table 4: The most Preferred Recreational Activity in Terms of Age, Gender Educational Level and Monthly Income

\begin{tabular}{|c|c|c|c|c|c|c|c|c|}
\hline \multirow[b]{2}{*}{ Recreation activity type } & \multicolumn{2}{|c|}{$\begin{array}{l}\text { Age } \\
\text { categories }\end{array}$} & \multicolumn{2}{|c|}{ Gender } & \multicolumn{2}{|c|}{$\begin{array}{l}\text { Educational } \\
\text { qualifications }\end{array}$} & \multicolumn{2}{|c|}{$\begin{array}{l}\text { Income } \\
\text { categories }\end{array}$} \\
\hline & $\mathrm{Ag}^{-1}$ & $\mathrm{Ag}^{-2}$ & $\mathrm{G}^{\mathrm{m}}$ & $G^{f}$ & $\mathrm{Ed}^{-1}$ & $\mathrm{Ed}^{-2}$ & $\mathrm{Mi}^{-1}$ & $\mathrm{Mi}^{-2}$ \\
\hline Watching soccer/ other sports in parks & 19.7 & 21.5 & 31.0 & 10.6 & 20.2 & 18.3 & 24.7 & 23.3 \\
\hline Playing soccer game & 15.5 & 13.4 & 21.1 & 11.1 & 17.3 & 14.5 & 14.7 & 10.4 \\
\hline Taking beer/other drinks at pubs/ parks & 23.8 & 19.8 & 33.2 & 6.6 & 12.5 & 22.9 & 18.4 & 12.8 \\
\hline Riding bicycles /motor cycles & 12.8 & 10.2 & 2.7 & 9.5 & 2.8 & 8.3 & 8.4 & 9.0 \\
\hline Visiting museums & 14.2 & 11.2 & 2.2 & 23.8 & 12.3 & 11.4 & 10.5 & 14.7 \\
\hline Taking leisure walks/trekking & 1.8 & 4.8 & 3.6 & 12.3 & 11.3 & 2.6 & 4.2 & 13.3 \\
\hline Picnicking & 2.7 & 2.9 & 1.8 & 3.1 & 6.5 & 1.5 & 3.1 & 4.7 \\
\hline Visiting Zoo & 2.7 & 1.7 & 1.1 & 1.5 & 3.6 & 4.5 & 5.7 & 5.7 \\
\hline Playing basketball & 2.2 & 2.9 & 0.7 & 3.9 & 5.7 & 6.1 & 3.6 & 1.9 \\
\hline Taking photograph & 0.9 & 1.7 & 0.7 & 4.7 & 6.5 & 3.0 & 2.1 & 1.4 \\
\hline $\begin{array}{l}\text { Others (mountain climbing, } \\
\text { swimming, playing tennis etc) }\end{array}$ & 3.2 & 1.1 & 1.4 & 1.5 & 2.8 & 6.4 & 4.2 & 2.8 \\
\hline
\end{tabular}

Notes:

$\mathrm{Ag}^{-1}=$ participants below 40years age

$\mathrm{Ag}^{-2}=$ participants of 40years age and above

$\mathrm{G}^{\mathrm{m}}=$ male participants

$\mathrm{G}^{\mathrm{f}}=$ females participants

$\mathrm{Ed}^{-1}=$ graduate participants

$\mathrm{Ed}^{-2}=$ non graduates participants

$\mathrm{Mi}^{-1}$ = family income below N100, 000

$\mathrm{Mi}^{-2}$ = family income of N100, 000 and above

According to Table 4, the most preferred activity to the greater percent of participants below 40years is taking beer/other drinks with friends in pubs and parks while watching soccer matches and other games in public parks is most preferred by participants that are 40 years or older. Playing soccer game and visiting museums are still important recreational activities for the two age groups; however, there is a significant difference in the level of participation between the two groups. From the responses, interest in playing soccer seem to decrease with age as level of participation drops from $15.5 \%$ among the younger participants below 40 years to $13.4 \%$ among the older participants of 40years and older population. Also there is a similar decreasing level of participation in visiting museums among participants who aged 40 years and above as compared to similar figures for the younger participants below 40 years. Furthermore, differences in the most preferred activity also exist between the male and female respondents. The larger percent of the male respondents (33.3\%) mostly prefer taking beer/other drinks with friends in parks or pubs during leisure time, while the most preferred activity to the greater percent of the sampled female population $(23.8 \%)$ is visiting museums. Variations also exist 
on the basis of participants' level of education. To the larger percent $(20.2 \%)$ of participants with at least a university degree or its equivalent, watching soccer /other sports in parks is the most preferred outdoor recreational activity. The second and third largest percents $(17.3 \%$ and $12.5 \%)$ of the group still preferred playing soccer and taking beer/ other drinks at parks and in pubs. These figures however, change with the group of participants who had lower educational qualifications. To the larger percent of this group (22.9\%), taking beer/other drinks at public parks and in pubs is the most preferred activity followed by watching soccer/ other sport games in parks. On the other hand, there is also a decreasing interest in trekking as an act of recreation with increasing educational levels.

This study also revealed important results about influences of income on recreation activity preference. The most preferred types of recreation activities seem to change with participants' monthly incomes. It shows that though watching soccer games in parks and playing soccer are two important preferred activities by families earning below N100000 monthly incomes and those earning N100000 and above, the level of interests in these activities significantly declines with increasing monthly incomes. Thus interest in participation in these activities is evidently higher among participants whose monthly incomes are below N100, 000 than that of the higher income families earning. This result therefore corroborates the earlier findings in Minna, Nigeria by Nelson et al (2013) that most low income residents of the city dedicate most of their recreation time in watching soccer sports. On the other hand, interest in visiting museum seems to increase with participants' family income. Thus while visiting museums is most important recreation activity to only $10.5 \%$ of the lower income participants, it is most preferred by $15 \%$ of the higher income group.

\section{Summary and Conclusion}

In summary, this study has been able to analyse the recreational behavior and preferences of residents in the federal capital city Abuja. Generally residents of the city show strong inclination to recreation during leisure time. It was found that over two thirds of the population dedicates their leisure time to either indoor or outdoor recreational activities. Only less than one third of the population indulges in non recreational activities. The study further reveals six activities of recreation most preferred by residents of the city which in a decreasing order of importance include: watching soccer matches/other sports, playing soccer games and taking beer / other drinks in pubs. Others include bicycling, visiting historical museums and trekking. Again the study showed that preferences for activities of recreation by the people do change with age, gender, educational level and income. Although the changes were not too dramatic, younger people below 40 years most prefer taking drinks in parks and pubs while people of 40 years and older prefer watching soccer matches. Also it was found that while the dominant male population preferred taking alcoholic drinks, their female counterpart showed high interest in visiting museums. Furthermore the graduate population according to the report place higher premium to watching 
soccer and sports while non graduates expressed more interest in taking beer /other drinks. Again the lower income group was most inclined to watching soccer matches while the higher income groups preferred visiting museums. Beside the preferences of the dominant populations in the same age, gender, education and income categories, are also the preferences of the minorities in these categories.

For effective recreation planning therefore, allocation of resources for the provision of recreational facilities in the city should not only be with due consideration of the preferences of the larger percent of the categories, but should also reflect that of the minorities in the same age, gender, educational level and monthly income categories. This will act as a guide towards adequacy of the facilities for the needs of all groups thereby averting abandonment or underutilization of facilities or over utilization of facilities due to high pressure on them

\section{References}

Austin, D. (2003). Therapeutic Recreation: Processes and Techniques. 5th ed. (Champaign, Il: Sagamore publishing, 181.

Australian National Centre for Culture and Recreation Statistics (2007). Motivators and Constraints to Participation in Sports and Physical Recreation. Report prepared for the Standing Committee on Recreation and Sport Research Group.

Broadhurst, R. (2001). Managing Environments for Leisure and Recreation, London, Routledge. Dwyer, J.F. and Baro, S.C. (2001). Outdoor recreational behavior and preferences of urban racial ethnic groups. An example from Chicago area. In Gerald Kyle comp. ed. Proceedings of 2000 North Eastern Recreation Research

Gray, D. and Seymour, G. (1974). "Future Perspectives," Parks and Recreation: 49.

Haley, A.J. (1979). Municipal recreation and park standards in the United States: Central cities \& suburbs. Leisure Sciences, 2(3/4): 21-34.

Haley, A.J. (1985). Municipal recreation and park standards in the United States: Central cities \& suburbs, 1975-1980. Leisure Sciences, 7(2): 48-72.

Jensen, E.L. and Ouis, P. (2008). Contested construction of nature for city fringe outdoor recreation in Southern Sweden: The Arie case, Urban Forestry and Urban Greening. V. 7.

Jibril, I.U. (2010). The Return of the Greens in Abuja, Nigeria's new Capital City: Facing the Challenges - Building the Capacity. Sydney, Australia, 11-16.

Kara, F. and Demirci, A. (2010). An Assessment of Outdoor Recreational Behaviour and Preferences of the Residents in Istanbul. Scientific research and Essay, 5(1): 93-104

Nelson, A.R., Martins, V.I and Bello, L.O. (2013). An Assessment of Preference and Behavior of Minna City Dwellers to outdoor recreation. International Journal of Humanities and Socioscience invention, 3(2): 17-30.

Patmore, J.A. (1983). Recreation and Resources: Leisure Patterns and 
Leisure Places. London, UK: Basil Blackwell.

Payne, L.L., Mowen, A.J. and OrsegaSmith (2002.) An Examination of Park Preferences and

Behaviors Among Urban Residents: The Role of Residential Location, Race, and Age. Leisure Sciences, 24(1): 104-118.

Riddick, C. and Stewart, D.G. (1994). An Examination of Life Satisfaction and Importance of Leisure in the lives of Older Females: A comparison of Blacks to Whites. Leisure Research, 26(1): 19-35.

Roskaft, E. (2004). Patterns of outdoor Recreation Activities among
Norwegians: An Evolutionary Approach. Retrieved from http://www.researchgate.net

Scott, D. and Jackson, E.L. (1996). Constraints to Leisure. In E.L. Jackson and Burtons (Eds.) Leisure studies: Prospects for the twentyfirst century. State College, PA, Venture Pubs.

Schroeder, H. (1983). Variations in the perception of urban forest recreation sites. Leisure Sciences, 5(3): 95-107.

Zandersen, M. and Tol, R.S.J. (2008). A meta-analysis of forest recreation values in Europe. Journal of Forestry Economics, 28(1): 52-74. 